\title{
Türkiye A Milli Kadın Hentbolcuların Omuz ve Bacak Kas Kuvvet Değerlerinin Sürat, Kuvvet ve Dayanıklıık Performansı ile İlişkisi: Türkiye Örneği
}

\section{The Relation Between Speed, Strength, Endurance and Shoulder and Leg Muscle Strength in Turkey National Women Handball Team Players: Sample from Turkey}

\author{
Hikmet Vurgun $^{1 *}$, Nilgün Vurgun ${ }^{1}$, Turan Işık ${ }^{1}$, Mustafa Engür ${ }^{2}$, Canan Aldırmaz ${ }^{3}$, Mustafa Kara ${ }^{4}$ \\ ${ }^{1}$ Celal Bayar Üniversitesi Spor Bilimleri Fakültesi, Manisa, Türkiye \\ ${ }^{2}$ Ege Üniversitesi Spor Bilimleri Fakültesi, İzmir, Türkiye \\ ${ }^{3}$ Millî Eğitim Bakanlığı, İl Milli Eğitim Müdürlüğü, Manisa, Türkiye \\ ${ }^{4}$ Celal Bayar Üniversitesi Sağlık Bilimleri Enstitüsü Dr. Öğrencisi, Manisa, Türkiye \\ e-posta: hvurgun@yahoo.com,nilvurgun@hotmail.com, turan_20032003@yahoo.com, \\ mengur@gmail.com, cananaldirmaz@gmail.com, mustafa_egebesyo@hotmail.com \\ ORCID: 0000-0001-6779-8000 \\ ORCID: 0000-0001-7856-3303 \\ ORCID: 0000-0001-8047-510X \\ ORCID: 0000-0001-9435-9951 \\ ORCID: 0000-0001-8145-6066 \\ ORCID: 0000-0002-9794-2445 \\ *Sorumlu Yazar / Corresponding Author: Hikmet Vurgun
}

Gönderim Tarihi / Received: 10.02.2020

Kabul Tarihi / Accepted: 18.06.2020

DOI: $10.34087 /$ cbusbed.687453

\begin{abstract}
Giriş ve Amaç: Bu çalışma, elit düzeydeki kadın hentbolcularda dominant ve nondominant bacak ve omuzda 60 ve $300^{\circ}$ sn açısal hızlardaki diz ekstansiyon-fleksiyon (E-F) ve omuz internal-eksternal (İ-E) izokinetik kuvvet ölçüm performanslarını ve oluşan bilateral kuvvet farklılıklarını saptamayı ve belirlenen bu izokinetik kuvvet ölçümlerinden dominant ve nondominant diz ekstansiyon ve fleksiyon zirve tork değerlerinin sprint, çeviklik, dayanıklılık ve 5 tekrarlı squat; dominant ve nondominant omuz internal ve eksternal zirve tork değerlerinin de 5 tekrarlı bench press ile olan korelasyonu belirlemeyi amaçlamaktadır.
\end{abstract}

Gereç ve Yöntemler: Bu çalışmaya Türkiye Kadın A-Milli Hentbol Takımında yer alan 15 sporcu gönüllü olarak katılmıştır. Çalışma süresince çeviklik, sürat, 5 tekrarlı maksimal squat ve bench press, izokinetik ölçümler ve 3000 $\mathrm{m}$ dayanıklılık değerlendirilmiştir. İlk test gününde $\mathrm{T}$ çeviklik testi ve $0-30 \mathrm{~m}$ sürat testi yapılmıştır. İkinci test gününde 5 tekrarlı maksimal squat ve bench press testleri gerçekleştirilmiştir. Üçüncü test gününde diz ekstansiyonfleksiyon ve omuz internal-eksternal izokinetik kuvvet ölçümleri yapılmıştır. Son test gününde ise $3000 \mathrm{~m}$ dayanıklılık testi uygulanmıştır.

Bulgular: İstatistiksel sonuçlara göre $60^{\circ}$ ve $300^{\circ} / \mathrm{sn}$ açısal hızlardaki dominant-nondominant diz fleksiyonekstansiyon ve omuz internal zirve tork değerleri arasında anlamlı farklar belirlenmiştir $(\mathrm{p}<0,05)$. İzokinetik ölçümlerle sprint, çeviklik, dayanıklılık ve 5 tekrarlı bench press ve squat performansları arasında anlamlı korelasyon bulunmamıştır ( $>>0,05)$. Sadece $60 \%$ sn açısal hızlardaki dominant bacak diz fleksiyon zirve tork değerleri ile $3000 \mathrm{~m}$ dayanıklılık testi arasında ve $300 \%$ sn nondominant omuz internal ile bench press arasında anlamlı korelasyon görülmüştür $(\mathrm{p}<0,05)$.

Sonuçlar: Bu çalışmanın bulguları Türkiye Kadın A-Milli Hentbol Takımı oyuncuların daha fazla kuvvet antrenmanı yapmaları gerektiğini göstermektedir. Hentbolda izokinetik dominant-nondominant omuz ve bacak kuvveti ile çeviklik, sürat, 5 tekrarlı squat ve bench press ve dayanıklılık arasında bir korelasyon bulunamamıştır.

Anahtar kelimeler: Hentbol, İzokinetik Ölçüm, çabukluk, sürat, kuvvet, dayanıklılık. 


\begin{abstract}
Objective: The aim of the study is to evaluate bilateral differences in concentric contraction mode of peak torqe knee extension - flexion and shoulder internal - external isokinetic strength of the dominant and non-dominant leg and shoulder at angular velocities 60 and 3000/sec in Turkish Women National Handball Team Players and to investigate the correlation between sprint, agility, endurance, 5 repetitives squad performance and knee extension - flexion and also correlation between 5 repetitives bench press and shoulder internal - external at angular velocities 60 and 3000/sec.

Materials and Methods: Fifteen National Handball Team players voluntarily participated in this study. Agility, speed, 5 repetitive maximal squat and bench press, isokinetic measurements and endurance tests were evaluated during the study. Agility tests performed on the first test day, maximal squat and bench press tests were performed on the second test day. Isokinetic strength measurements of knee $\mathrm{n}$ and shoulder were performed on the third test day. Last day endurance test were performed.

Results: According to results, significant differences were found between dominant-nondominant knee flexionextension peak torque values at angular velocities of 600 and shoulder internal peak torque value at angular velocities of 3000/sn $(p<0,05)$. There was only one significant correlation between endurance and dominant leg knee flexion peak torque value at angular velocity of $600 / \mathrm{sn}$ and between bench press test and nondominant shoulder internal peak torque value at angular velocity of $3000 / \mathrm{sn}(\mathrm{p}<0,05)$.

Conclusion: The findings of this study show that Turkish Women National Handball Team players need to practice strength training more than before. There was no corelation between isokinetic dominant-nondominant shoulder and leg strength at angular velocities of $600 / \mathrm{sn}$ and 3000/sn with agility, sprint, 5 repetitive squat and bench press and endurance in handball.
\end{abstract}

Keywords: Handball, isokinetic measurement, agility, sprint, strength, endurance.

\section{Giriş}

Antrenörlerin sporcuların hedeflenen gelişimlerini sağlaması için ilgili spor branşının fiziksel, fizyolojik ve metabolik taleplerini bilmesi ve antrenmanlarını bu talepler doğrultusunda dizayn etmesi sporcunun müsabakada daha iyi bir performans göstermesi için gerekli olan fiziksel kalite ve tekniksel becerilerin ortaya konmasında fonksiyonel koşul olarak gereklidir [1].

Ayrıca ilgili branşın fizyolojik taleplerine göre uygulanan çalışmaların doğruluğu veya yararı, uygulanan testlerle ya da alınan sonuçlara bakılarak da değerlendirilmesi oldukça önemlidir. Bu amaçla performansin saha ve laboratuvar testleri ile değerlendirilmesi, sporcuların yeteneklerinin teşhis edilmesine ve oynadıkları pozisyonlara göre belirli becerilerin geliştirilmesine yönelik antrenman programlarının tasarlanmasına, sporcunun kuvvetsizliğinden kaynaklanan yaralanmaların önlenmesinde ve sakatlıkların tedavisindeki uygun programların oluşturulmasına ve sezon boyunca oyuncuların gelişimlerinin kayıt altına alınmasına olanak sağlayarak antrenman planlarının yeniden yapılandırılmasında yeni bir araç ve strateji oluşturmaktadır [2, 3, 4].

Hentbol oyununda motorik ve fizyolojik özellikler sportif başarıya ulaşmada önemli rol oynamaktadır. Hentbol için öncelikli motorik özellikler; hareketlilik, sürat, sıçrama, atış kuvveti, dayanıklılık ve koordinasyondur [5]. Birebir temasa dayanan hentbol oyunu, bir oyuncunun iyi bir fiziksel hazırlık yapmasını gerektirir. Hentbol oynayan sporcular düzgün bir postüre sahiptir, çünkü bir müsabakada tüm vücut kasları kullanılmaktadır. Üst ve alt ekstremitelerin tüm eklemlerinin çalıştığ 1 devamlı hareketler, eklem hareket açısını (range of motion) geliştirir ve arttırır.
Hentbolcular, atış, paralel dalma, blok ve top kontrolü gibi birçok fiziksel beceriye sahiptir. Hentbol, vücudun her iki tarafını da aerobik aktivite, kas kuvveti, denge ve esneklik ile birlikte eşit olarak çalıştırır. Koşu, sprint ve sıçrama gibi yoğun/şiddetli, aralıklı faaliyetlerin yanı sira oyuncular arasında düzenli atış, vurma, blok ve itme gibi faaliyetlerden oluşur [6, 7]

Dolayisıyla hentbolda alt ve üst ekstremitelerde yüksek nöromüsküler talepler oluşturan aktivitelerin elit düzeyde başarılı bir şekilde gerçekleştirilmesi için sporcuların iyi düzeyde antropometrik özelliklere, iyi gelişmiş dayanıklılık, kas gücü, sürat, çeviklik ve savurma hızına sahip olmaları gereklidir [8].

Hentbolda başarı için en önemli beceri atış kabiliyetidir ve atış verimliliği açısından en önemli faktörlerden biri de üst ve alt ekstremite kas kuvveti ve gücüdür [9]. Kas gücü, hentbolda oyun performansının en önemli fiziksel bileşenlerinden biridir.

Kas gücünün doğru bir şekilde değerlendirilmesinde tork değerlerini ölçmek için izokinetik değerlendirme kullanılabilir. İzokinetik dinamometre ile değerlendirme, kas gücünün basitçe belirlenebilmesi için nesnel bir yaklaşım sağlamak adına altın standart olarak kullanılmaktadır [10].

$\mathrm{Bu}$ çalışma, elit düzeydeki kadın hentbolcularda dominant ve nondominant bacak ve omuzda 60 ve $300 \%$ sn açısal hızlardaki zirve tork diz ekstansiyonfleksiyon (E-F) ve omuz internal-eksternal (İ-E) izokinetik kuvvet performanslarını ve performans sonrası oluşan bilateral kuvvet farklılıklarını saptamayı ve belirlenen bu izokinetik kuvvet ölçümlerinden dominant ve non-dominant bacak diz ekstansiyon-fleksiyon zirve tork değerlerinin sprint, 
çeviklik, dayanıklılık ve 5 tekrarlı squat; dominant ve non-dominant omuz internal-eksternal zirve tork değerlerinin de 5 tekrarlı bench press ile olan ilişkisini belirlemeyi amaçlamaktadır.

\section{Materyal ve Metod}

$\mathrm{Bu}$ çalışma, Türkiye Hentbol Federasyonu (THF) Kadın A-Milli Hentbol Takımının hazırlık kampı süresince milli takımda düzenli olarak oynayan, çalışma süresince son 6 ayda herhangi bir sakatlık geçirmemiş ve lig sezonu boyunca düzenli olarak haftalık antrenmanların tümüne katılan gönüllü 15 kadın profesyonel sporcudan oluşmuştur $(24,6 \pm 4,48$

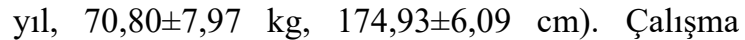
öncesinde gönüllü olur formu kullanılarak katılımcıların çalışmaya katılım onamları alınmıştır. Çalışma öncesinde çalışmaya ait olan ilgili ölçüm ve uygulamalar için Manisa Celal Bayar Üniversitesi Spor Bilimleri Fakültesi Dekanlığından gerekli izinler ve CBÜ Tıp Fakültesinden Etik Kurul Raporu alınmıştır.

Yaptığımız çalışmada yer alan tüm katılımcıların üzerindeki yorgunluk faktörünü minimize etmek için ölçümler öncesindeki 48 saat boyunca herhangi bir yorucu egzersiz yaptırılmamıştır. Çalışmanın hemen öncesinde 15 dakikalı genel 1sınma protokolü uygulanmıştır. Çalışmanın 1. gününde $\mathrm{T}$ çeviklik testi spor salonunda düz bir zeminde kablosuz sistem ile çalışan çift fotoelektriksel zamanlama kapılarından oluşan smartspeed kullanılarak ölçülmüştür. 3 huni aralarında 4,57 metre mesafe olacak şekilde aynı hizaya yerleştirilmiş ve teste, başlangıç noktası ortada yer alan huniden 9,14 m geride olacak şekilde yerleştirilmiş huniden başlanılmıştır. Her bir sporcuya testi gerçekleştirmesi için 3 hak sağlanmış ve her bir test arasında sporculara 3 dakikalık dinlenme verilmiştir. Toplamda üç kez yapılacak olan testin derecelerinin ortalaması sn cinsinden kaydedilmiştir [11].

$30 \mathrm{~m}$ sprint testi, T çeviklik testini takiben kablosuz sistem ile çalışan çift kapılı smartspeed (Fusion Sport, Avustralya) kullanılarak ölçülmüştür. Zamanlama kapılarından ilki başlangıç, ikincisi ise
$30 \mathrm{~m}$ bitiş çizgisine yerleştirilmiştir. Test 2 tekrardan oluşmuş ve gerçekleştirilen en iyi zaman saniye cinsinden analizler için kullanılmıştır [12].

5 tekrarlı maksimal squat ve bench pres testleri çalışmanın 2. günü fitnes salonunda yapılmıştır. Her bir sporcunun kaldırabileceği tahmini ağırlık başlangıç yükü olarak belirlenmiştir. Başarılı olarak kaldırılan her bir set sonrası 1 dakikalık dinlenme verilmiş ve bir sonraki kaldırış için ilave ağırlık eklenerek harekete devam edilerek 5 tekrarlı maksimal squat ve bench press değerleri bulunmuştur [13].

Çalışmanın 3. gününde dominant ve nondominat omuz ve bacakta 60 ve $300 \%$ sn açısal hizlarda konsantrik - konsantrik 5 tekrarlı zirve tork diz ekstansiyon- fleksiyon ve omuz internal- eksternal izokinetik dinamometre ölçümleri yapılmıştır. Ölçümler, konsantrik fazda diz ekstansiyonfleksiyon ile başlamış ve ölçüme başlama bacağ rastgale seçim yöntemiyle belirlenmiştir [14,15]. Sporcuların izokinetik dinamometreye olan izolasyon ve stabilizasyonun sağlanmasından sonra 5 tekrarlı submaksimal 1sınma ve cihaza uyum ölçümü yapılmıştır. 30sn'lik dinlenme sonrasında ise $60 \%$ açısal hızda maksimal kas kuvvetini değerlendirmek için 5 tekrarlık maksimal test ölçümü alınmıştır [16, 17]. Aynı işlemler çabuk kuvveti değerlendirmek için $300 \%$ sn açısal hızlarda da tekrar edilmiştir. Diz ekstansiyon - fleksiyon ölçümünü takiben omuz internal ve eksternal ölçümleri aynı protokol kullanılarak gerçekleştirilmiştir. Değerlendirmede 5 tekrarlı maksimal ölçümün hangisinde en yüksek zirve tork değeri elde edildiyse o veri analizde kullanılmıştır [18].

$3000 \mathrm{~m}$ dayanıklılık performansı çalışmanın son günüde 400 metrelik atletizm pistinde gerçekleştirilmiştir. 3000 metre koşu süreleri alınan sporcuların $\mathrm{VO}_{2 \text { maks }}$ değerleri, Mercier ve arkadaşları tarafından 1986 yılında oluşturulmuş nomogram ile tahmin edilmiştir [19]. Yaptığımız araştırmanın çalışma dizaynı Tablo 1'de gösterildiği gibi gerçekleştirilmiştir.

Tablo 1. Çalışma süresince uygulanan testler ve çalışma takvimi

\begin{tabular}{|l|c|c|c|c|}
\hline Testler & 1. Gün & 2. Gün & 3. Gün & 4. Gün \\
\hline T Çeviklik Testi & \multicolumn{1}{|l|}{} & & \\
\hline 0-30 m Sprint Testi & $\checkmark$ & & & \\
\hline 5 Tekrarlı Maksimal Squat-Bench Press & & & & \\
\hline İzokinetik Testler & & & & \\
\hline 3000 m Dayanıklılı Testi & & & & \\
\hline
\end{tabular}

\section{1 İstatistiksel analiz}

Çalışmada elde edilen verilerin istatistiksel analizi, SPSS 22.0 (SPSS Inc.) istatistik programı kullanılarak yapılmıştır. Öncelikle analizi yapılan verilerin ortalama ve standart sapma değerleri hesaplanmıştır. Daha sonra tüm istatistiksel işlemler öncesinde verilerin, normal dağılım gösterip göstermediğini belirlemek için Shapiro-Wilk Testi uyguanmıştır. Bu test sonucunda elde edilen 
verilere göre grupların normal dağılım gösterdiği tespit edilmiştir ( $p>0,05)$. Normal dağılım gösteren bu verilerin 60 ve $300^{\circ}$ /sn açısal hızlardaki dominant ve non-dominant diz ekstansiyon ve fleksiyon, omuz internal ve eksternal zirve tork değeri bileteral farklılıklarının istatistiksel analizi, paired sample $\mathrm{t}$ test kullanılarak yapılmıştır. Ayrıca 60 ve $300 \%$ sn açısal hılardaki dominant ve non-dominant bacaktaki diz ekstansiyon-fleksiyonda ölçülen izokinetik zirve tork değerinin $30 \mathrm{~m}$ sürat, $\mathrm{T}$ çeviklik, $3000 \mathrm{~m}$ dayanıklılık ve 5 tekrarlı squat; aynı açısal hızlardaki dominant ve non-dominant omuzdaki ölçülen internal-eksternal zirve tork değerlerinin 5 tekrarlı bench press performansı ile olan korelasyonun belirlenmesi için pearson korelasyonu kullanılmıştır. Veriler arasındaki anlamlılığın pearson korelasyon katsayısı ( $\mathrm{r}$ ); 0,00 - 0,19 çok küçük, 0,20 - 0,39 küçük, 0,40 - 0,59 orta, 0,60 - 0,79 yüksek ve $0,80-1,00$ çok yüksek olarak belirlenmiştir (Wuensch ve Evans 2006). Verilerin istatistiksel analizinde güven aralığı $\% 95$ olarak seçilmiş ve $\mathrm{p}<0,05$ 'in altındaki değerler anlamlı kabul edilmiştir.

\section{Bulgular}

Tablo 2 incelendiğinde katılımcıların $60^{\circ}$ ve $300^{\circ} / \mathrm{sn}$ açısal hızlardaki dominant ve nondominant diz fleksiyon-ekstansiyon zirve tork değerleri PairedSamples T Testi ile karşılaştırılmıştır. Test sonucuna göre, $60 \%$ sn açısal hızdaki dominant bacak diz ekstansiyon zirve tork değeri ortalaması $(60 \%$ sn dom. diz eks. $=143,54)$ ile nondominant bacak diz ekstansiyon zirve tork değeri ortalaması $(60 \%$ sn nondom. diz eks. $=135,17)$ arasinda anlamlı bir fark tespit edilmiştir [t $(14)=4,774, \mathrm{p}<0,05]$. Bununla beraber analizi yapılan $300 \%$ sn açısal hızdaki dominant bacak diz ekstansiyon zirve tork değeri ortalamas1 $(300 \%$ sn dom. diz eks. $=43,24)$ ile nondominant bacak diz ekstansiyon zirve tork değeri ortalamas1 $(300 \%$ sn nondom. diz eks. $=38,84)$ arasında da anlamlı bir fark tespit edilmiştir $[\mathrm{t}(14)=$ 5,564, $\mathrm{p}<0,05]$.

Tablo 2. Çalışmada yer alan katılımcıların 60 ve 300/sn açısal hızlardaki dominant ve nondominant diz fleksiyonekstansiyon zirve tork değerlerinin karşılaştırılması

\begin{tabular}{|c|c|c|c|c|}
\hline & \multicolumn{2}{|c|}{ Diz Ekstansiyon (Nm) } & \multicolumn{2}{c|}{ Diz Fleksiyon (Nm) } \\
\hline \multirow{2}{*}{ Dominant } & $\mathbf{6 0} / \mathbf{s n}$ & $\mathbf{3 0 0} / \mathbf{s n}$ & $\mathbf{6 0} / \mathbf{s n}$ & $\mathbf{3 0 0} / \mathbf{s n}$ \\
\hline \multirow{2}{*}{ Non-Dominant } & $143,54 \pm 13,87$ & $43,24 \pm 6,48$ & $99,28 \pm 14,63$ & $39,86 \pm 10,33$ \\
\hline $\mathbf{t}$ & $135,17 \pm 13,48$ & $38,84 \pm 6,72$ & $84,10 \pm 10,84$ & $31,90 \pm 6,38$ \\
\hline $\mathbf{d f}$ & 4,774 & 5,564 & 6,706 & 4,988 \\
\hline $\mathbf{p}$ & 14 & 14 & 14 & 14 \\
\hline
\end{tabular}

$* \mathrm{p}<0,05$

Benzer şekilde $60^{\circ}$ ve $300^{\circ} /$ sn açısal hızlardaki dominant ve nondominant diz fleksiyon zirve tork değerlerinin analizleri de yapılmıştır. Buna göre $60 \%$ sn açısal hızdaki dominant bacak diz fleksiyon zirve tork değeri ortalaması ( $60 \%$ sn dom. diz flek. = $99,28)$ ile nondominant bacak diz fleksiyon zirve tork değeri ortalamas 1 ( $60^{\circ} / \mathrm{sn}$ nondom. diz flek. = 84,10) arasında anlamlı bir fark tespit edilmiştir $[\mathrm{t}(14)=6,706, \mathrm{p}<0,05]$. Bununla beraber analizi yapılan $300 \%$ sn açısal hızdaki dominant bacak diz fleksiyon zirve tork değeri ortalamas 1 ( $300 \%$ sn dom. diz flek. $=39,86)$ ile nondominant bacak diz ekstansiyon zirve tork değeri ortalaması ( 3000/sn nondom. diz flek. $=31,90)$ arasinda da anlamlı bir fark tespit edilmiştir [ $\mathrm{t}(14)=4,988, \mathrm{p}<0,05]$.
Tablo 3 incelendiğinde, katılımcıların $60^{\circ}$ ve $300^{\circ} / \mathrm{sn}$ açısal hızlardaki dominant ve nondominant omuz internal-eksternal zirve tork değerleri PairedSamples T Testi ile karşılaştırılmıştır. Test sonucuna göre, $60 \%$ sn açısal hızdaki dominant omuz internal zirve tork değeri ortalamas $1\left(\bar{x}_{60}{ }^{0} /\right.$ sn dom. omuz I. $\left.=62,81\right)$ ile nondominant omuz internal zirve tork değeri ortalamas1 $\left(\bar{x}_{60}{ }^{\circ}\right.$ sn nondom. omuz ì. $\left.=52,50\right)$ arasinda anlamlı bir fark tespit edilmiştir $\left[\mathrm{t}_{(14)}=4,499, \mathrm{p}<0,05\right.$ ]. Bununla beraber analizi yapılan $300 \%$ sn açısal hızdaki dominant omuz internal zirve tork değeri ortalamas1 $\left(\bar{x}_{300} /\right.$ sn dom. omuz ì. $\left.=25,96\right)$ ile nondominant omuz internal zirve tork değeri ortalaması $\left(\bar{x}_{300}{ }^{0}\right.$ sn non-dom. omuz İ. $\left.=21,89\right)$ arasinda da anlamlı 
Tablo 3. Çalışmada yer alan katılımcıların 60 ve $300 \%$ sn açısal hızlardaki dominant ve nondominant omuz internal-eksternal rotasyon zirve tork değerlerinin karşılaştırılması

\begin{tabular}{|c|c|c|c|c|}
\hline & \multicolumn{2}{|c|}{ Omuz Internal Rotasyon (Nm) } & \multicolumn{2}{c|}{ Omuz Eksternal Rotasyon (Nm) } \\
\hline & $\mathbf{6 0} \%$ sn & $\mathbf{3 0 0} \%$ sn & $\mathbf{6 0} \%$ sn & $\mathbf{3 0 0} \%$ sn \\
\hline Dominant & $62,81 \pm 8,80$ & $25,96 \pm 7,33$ & $39,83 \pm 8,62$ & $21,06 \pm 4,17$ \\
\hline Non-Dominant & $52,50 \pm 6,73$ & $21,89 \pm 5,56$ & $41,67 \pm 7,73$ & $20,71 \pm 5,70$ \\
\hline $\mathbf{t}$ & 4,499 & 2,578 & $-0,620$ & 0,242 \\
\hline df & 14 & 14 & 14 & 14 \\
\hline $\mathbf{p}$ & $0,001 *$ & $0,021^{*}$ & 0,545 & 0,813 \\
\hline
\end{tabular}

$* \mathrm{p}<0,05$

bir fark tespit edilmiştir [t $(14)=2,578, \mathrm{p}<0,05]$. Benzer şekilde 60 ve $300 \%$ sn açısal hızlardaki dominant ve nondominant omuz eksternal zirve tork değerlerinin analizleri de yapılmıştır. Buna göre $60 \%$ sn açısal hızdaki dominant omuz eksternal zirve tork değeri ortalamas $1\left(\bar{x}_{60}{ }^{0}\right.$ sn dom. omuz E. $\left.=39,83\right)$ ile nondominant omuz eksternal zirve tork değeri ortalamas $1\left(\bar{x}_{60}{ }^{0}\right.$ sn nondom. omuz E. $\left.=41,67\right)$ arasinda anlamlı bir fark tespit edilmemiştir $\left[\mathrm{t}_{(14)}=-0,620\right.$, $\mathrm{p}>0,05$ ]. Bununla beraber analizi yapılan $300 \%$ sn açısal hızdaki dominant omuz eksternal zirve tork değeri ortalaması $\left(\bar{x}_{300}{ }^{\circ}\right.$ /sn dom. omuz E. $\left.=21,06\right)$ ile nondominant omuz eksternal zirve tork değeri ortalamas1 $\left(\bar{x}_{300}{ }_{\text {/sn nondom. omuz } \mathrm{E} .}=20,71\right)$ arasinda da anlamlı bir fark tespit edilmemiştir $\left[\mathrm{t}_{(14)}=0,242\right.$, $\mathrm{p}>0,05]$.

Tablo 4. Çalışmada yer alan katılımcıların $60^{\circ}$ ve $300^{\circ} / \mathrm{sn}$ açısal hızlardaki dominant bacak diz ekstansiyonfleksiyon zirve tork değerlerinin çeviklik testi, $30 \mathrm{~m}$ sürat testi, 5 tekrarlı maksimal squat testi, dayanıklılık testi ile olan pearson korelasyon katsayısı ilişkisi

\begin{tabular}{|c|c|c|c|c|c|}
\hline \multicolumn{6}{|c|}{ DOMINANT BACAK } \\
\hline & & $\begin{array}{c}\text { Diz } \\
\text { Ekstansiyon } \\
60^{\circ} / \mathrm{Sn} .\end{array}$ & $\begin{array}{c}\text { Diz Fleksiyon } \\
60^{\circ} / \mathrm{Sn} .\end{array}$ & $\begin{array}{c}\text { Diz } \\
\text { Ekstansiyon } \\
\mathbf{3 0 0} / \text { Sn. }\end{array}$ & $\begin{array}{c}\text { Diz Fleksiyon } \\
300 \% \text { Sn. }\end{array}$ \\
\hline \multirow[t]{2}{*}{$\begin{array}{l}\text { T Çeviklik } \\
\text { Testi }\end{array}$} & $\begin{array}{c}\text { Pearson } \\
\text { Korelasyonu }\end{array}$ & 0,108 & 0,156 & $-0,174$ & 0,238 \\
\hline & $P$ & 0,703 & 0,578 & 0,534 & 0,394 \\
\hline \multirow[t]{2}{*}{$30 \mathrm{~m}$. Sürat } & $\begin{array}{c}\text { Pearson } \\
\text { Korelasyonu }\end{array}$ & 0,070 & 0,200 & $-0,150$ & 0,227 \\
\hline & $P$ & 0,806 & 0,475 & 0,594 & 0,415 \\
\hline \multirow[t]{2}{*}{5 TM Squat } & $\begin{array}{c}\text { Pearson } \\
\text { Korelasyonu }\end{array}$ & 0,231 & 0,210 & 0,096 & 0,264 \\
\hline & $P$ & 0,407 & 0,453 & 0,733 & 0,341 \\
\hline \multirow[t]{2}{*}{$\begin{array}{l}\text { 3000m. } \\
\text { Dayanıklılık }\end{array}$} & $\begin{array}{c}\text { Pearson } \\
\text { Korelasyonu }\end{array}$ & 0,257 & 0,605 & 0,132 & 0,501 \\
\hline & $P$ & 0,354 & $0,017 *$ & 0,638 & 0,057 \\
\hline
\end{tabular}

Tablo 4 incelendiğinde, $60 \%$ sn açısal hızdaki dominant bacak diz ekstansiyon $(r=0,108 ; p=0,703)$, diz fleksiyon $(r=0,156 ; p=0,578)$ ve $300^{\circ} /$ sn açısal hizdaki dominant bacak diz ekstansiyon $(\mathrm{r}=-0,174$; $\mathrm{p}=0,534), \quad$ diz fleksiyon $(\mathrm{r}=0,238 ; \mathrm{p}=0,394)$ değerlerinin çeviklik testi değerleri ile ilişkili olmadığ 1 belirlenmiştir ( $>>0,05) . \quad 60 \%$ sn açısal hizdaki dominant bacak diz ekstansiyon $(\mathrm{r}=0,070$; $\mathrm{p}=0,806)$, diz fleksiyon $(\mathrm{r}=0,200 ; \mathrm{p}=0,475)$ ve $300 \%$ açısal hızdaki dominant bacak diz ekstansiyon ( $\mathrm{r}=-0,150 ; \mathrm{p}=0,594)$, diz fleksiyon $(\mathrm{r}=0,227 ; \mathrm{p}=0,415)$ değerlerinin $30 \mathrm{~m}$ sürat testi

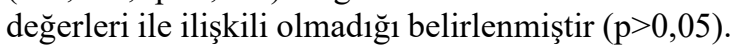

Katılımcıların, $60 \%$ sn açısal hızdaki dominant bacak diz ekstansiyon ( $r=0,231 ; \mathrm{p}=0,407)$, diz fleksiyon $(\mathrm{r}=0,210 ; \mathrm{p}=0,453)$ ve $300 \%$ sn açısal hızdaki dominant bacak diz ekstansiyon (r=-0,096; $\mathrm{p}=0,733), \quad \operatorname{diz}$ fleksiyon $(\mathrm{r}=0,264 ; \mathrm{p}=0,341)$ değerlerinin 5 tekrarlı maksimal squat testi değerleri ile ilişkili olmadığı belirlenmiştir ( $\mathrm{p}>0,05)$.

Son olarak, $60^{\circ} / \mathrm{sn}$ açısal hızdaki dominant bacak diz ekstansiyon $(\mathrm{r}=0,257$; $\mathrm{p}=0,354)$ ve $300 \%$ sn açısal hizdaki dominant bacak diz ekstansiyon $(\mathrm{r}=0,132$; $\mathrm{p}=0,638), \quad \operatorname{diz}$ fleksiyon $(\mathrm{r}=0,501 ; \mathrm{p}=0,057)$ değerlerinin $3000 \mathrm{~m}$ dayanıklılık testi değerleri ile ilişkili olmadığ $\breve{g}_{1}$ belirlenmiştir $(\mathrm{p}>0,05)$. 
Tablo 5. Çalışmada yer alan katılımcıların $60^{\circ}$ ve $300^{\circ}$ sn açısal hızlardaki nondominant bacak diz ekstansiyonfleksiyon zirve tork değerlerinin çeviklik testi, $30 \mathrm{~m}$ sürat testi, 5 tekrarlı maksimal squat testi, dayanıklılık testi ile olan pearson korelasyon katsayısı ilişkisi

\begin{tabular}{|c|c|c|c|c|c|}
\hline \multicolumn{6}{|c|}{ NON- DOMINANT BACAK } \\
\hline & & $\begin{array}{c}\text { Diz } \\
\text { Ekstansiyon } \\
60^{\circ} / \text { Sn. } \\
\end{array}$ & $\begin{array}{c}\text { Diz Fleksiyon } \\
\quad 60^{\circ} / \mathrm{Sn}\end{array}$ & $\begin{array}{c}\text { Diz } \\
\text { Ekstansiyon } \\
\text { 300\% } / \text { Sn. }\end{array}$ & 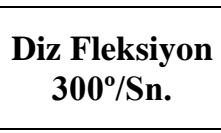 \\
\hline \multirow[t]{2}{*}{$\begin{array}{l}\text { T Çeviklik } \\
\text { Testi } \\
\end{array}$} & $\begin{array}{c}\text { Pearson } \\
\text { Korelasyonu }\end{array}$ & 0,136 & 0,148 & $-0,136$ & 0,178 \\
\hline & $P$ & 0,628 & 0,598 & 0,629 & 0,525 \\
\hline \multirow[t]{2}{*}{30 m. Sürat } & $\begin{array}{c}\text { Pearson } \\
\text { Korelasyonu }\end{array}$ & 0,012 & 0,050 & $-0,072$ & 0,042 \\
\hline & $P$ & 0,967 & 0,859 & 0,799 & 0,882 \\
\hline \multirow[t]{2}{*}{5 TM Squat } & $\begin{array}{c}\text { Pearson } \\
\text { Korelasyonu }\end{array}$ & $-0,144$ & $-0,079$ & $-0,078$ & $-0,121$ \\
\hline & $P$ & 0,608 & 0,779 & 0,781 & 0,668 \\
\hline \multirow[t]{2}{*}{$\begin{array}{l}\text { 3000m. } \\
\text { Dayantklılık }\end{array}$} & $\begin{array}{c}\text { Pearson } \\
\text { Korelasyonu }\end{array}$ & 0,285 & 0,433 & 0,197 & 0,397 \\
\hline & $P$ & 0,304 & 0,107 & 0,481 & 0,143 \\
\hline
\end{tabular}

$\mathrm{Bu}$ sonuçlara rağmen $60 \%$ sn açısal hızdaki dominant bacak diz fleksiyon $(\mathrm{r}=0,605 ; \mathrm{p}=0,017)$ değeri ile $3000 \mathrm{~m}$ dayanıklılık testi değerleri arasında anlamlı bir ilişki tespit edilmiştir $(\mathrm{p}<0,05)$. Test sonucuna göre, $60 \% \mathrm{sn}$ açısal hızdaki nondominant bacak diz ekstansiyon $(\mathrm{r}=0,012 ; \mathrm{p}=0,967)$, diz fleksiyon $(\mathrm{r}=0,050 ; \mathrm{p}=0,859)$ ve $300 \%$ açısal hızdaki nondominant bacak diz ekstansiyon ( $\mathrm{r}=-0,072 ; \mathrm{p}=0,799)$, diz fleksiyon $(\mathrm{r}=0,042$; $\mathrm{p}=0,882)$ değerlerinin $30 \mathrm{~m}$ sürat testi değerleri ile ilişkili olmadığı belirlenmiştir ( $\mathrm{p}>0,05)$.

$60 \%$ sn açısal hızdaki nondominant bacak diz ekstansiyon $(\mathrm{r}=-0,144 ; \mathrm{p}=0,608)$, diz fleksiyon $(\mathrm{r}=-0,079 ; \mathrm{p}=0,779)$ ve $300^{\%} / \mathrm{sn}$ açısal hızdaki nondominant bacak diz ekstansiyon ( $\mathrm{r}=-0,078 ; \mathrm{p}=0,781)$, diz fleksiyon $(\mathrm{r}=-$ $0,121 ; \mathrm{p}=0,668)$ değerlerinin 5 tekrarlı maksimal squat testi değerleri ile ilişkili olmadığı belirlenmiştir $(p>0,05)$. Yine aynı şekilde $60 \%$ sn açısal hızdaki nondominant bacak diz ekstansiyon ( $\mathrm{r}=0,285 ; \mathrm{p}=0,304)$, diz fleksiyon $(\mathrm{r}=0,433 ; \mathrm{p}=0,107)$ ve $300^{\%} / \mathrm{sn}$ açısal hızdaki nondominant bacak diz ekstansiyon ( $\mathrm{r}=0,197$; $\mathrm{p}=0,481)$, diz fleksiyon $(r=0,397 ; p=0,143)$ değerlerinin $3000 \mathrm{~m}$ dayanıklılık testi değerleri ile ilişkili olmadığ belirlenmiştir $(\mathrm{p}>0,05)$.

Katılımcıların $60 \%$ sn açısal hızdaki dominant omuz internal $(\mathrm{r}=0,045 ; \mathrm{p}=0,874)$, omuz eksternal $(\mathrm{r}=0,036$; $\mathrm{p}=0,900)$ ve $300 \%$ sn açısal hızdaki dominant omuz internal $(\mathrm{r}=0,277 ; \mathrm{p}=0,318)$, omuz eksternal $(\mathrm{r}=0,024$; $\mathrm{p}=0,934)$ değerlerinin 5 tekrarlı maksimal bench press testi değerleri ile ilişkili olmadığ belirlenmiştir $(\mathrm{p}>0,05)$. $60 \%$ sn açısal hızdaki nondominant omuz internal $(\mathrm{r}=0,258 ; \mathrm{p}=0,352)$, omuz eksternal $(\mathrm{r}=-0,282 ; \mathrm{p}=0,309)$ ve $300 \%$ sn açısal hızdaki nondominant omuz internal $(\mathrm{r}=0,599 ; \mathrm{p}=0,018)$, omuz eksternal $(\mathrm{r}=-0,063 ; \mathrm{p}=0,823)$ değerleri bulunmuş. $\mathrm{Bu}$ değerlerden sadece 5 tekrarlı bench press testi değerleri ile $300 \%$ sn açısal hızdaki nondominant omuz internal değeri arasında anlamlı bir ilişki belirlenmiştir $(\mathrm{p}<0,05)$.

\section{Tartışma}

$\mathrm{Bu}$ çalışmanın sonucunda elde edilen temel bulgu, konsantrik modda $60^{\circ}$ ve $300^{\circ} / \mathrm{sn}$ açısal hızlarda dominant-nondominant diz E-F ve omuz İ-E izokinetik kuvvet ölçüm değerleri arasında dominant bacak ve omuz lehine anlamlı farklılığın olduğudur. Ayrıca bu çalışmada Kadın A-Milli Hentbol Takımı oyuncularının $60^{\circ}$ ve $300^{\circ}$ sn açısal hızlarda dominant-nondominant diz E-F değerleri ile sürat, çeviklik, dayanıklılık ve 5 TM squat değerleri arasında bir korelasyonun olmadığ saptanmıştır.

Benzer sonuçlar omuz İ-E izokinetik kuvvet ölçüm değerleri ile $5 \mathrm{TM}$ bench press değerleri arasında da belirlenmiştir.

Zuzana Xaverova ve ark. 2015 yılında Çek-Slovak Süper Liginde oynayan 17 kadın hentbolcu üzerinde değişik açısal hızlarda dominant-nondominant diz E-F değerlerini izokinetik dinamometre ile karşılaştırmıştır [10]. $\mathrm{Bu}$ sporcu grubundan 9 kadın hentbolcu aynı zamanda son 3 yıldır kendi ülkelerinin milli takım oyuncusu olarak da görev almıştır [10]. $\mathrm{Bu} 9$ kadın hentbolcunun konsantrik-konsantrik $60 \%$ sn açısal hızda dominant diz E zirve tork değeri 154,9 $\pm 20,2(\mathrm{Nm})$, nondominant diz $\mathrm{E}$ zirve tork değeri 156,6 \pm 31,2 (Nm); dominant diz $\mathrm{F}$ zirve tork değeri $87,7 \pm 12,4(\mathrm{Nm})$, nondominant diz F zirve tork değeri 88,2 $\pm 15,7(\mathrm{Nm})$ olarak bulunmuş ve dominant-nondominant bacaklar arasında istatistiksel olarak anlamlı bir fark olmadığ rapor edilmiştir [10]. Yapılan başka bir çalışmada ise May A. Risberg ve arkadaşları 2018 yılında elit düzeydeki 196 kadın futbolcu ile 143 kadın hentbolcunun 600/sn açısal hızda dominant ve nondominant diz E-F değerlerini karşılaştırmıştır [20]. Yapılan bu çalışmada kadın hentbolcuların dominant bacak diz E zirve tork değeri ortalaması 166,3 $\pm 24,4(\mathrm{Nm})$, nondominant bacak diz E zirve tork değeri ortalaması 165,6 \pm 22,3 (Nm); dominant bacak diz F zirve tork değeri ortalaması 95,4 \pm 14,1 (Nm), nondominant bacak diz F zirve tork değeri 
ortalaması $93 \pm 12,6(\mathrm{Nm})$ olarak bulunmuş ve dominant ve nondominant bacak kuvvetleri arasında bir farklılık

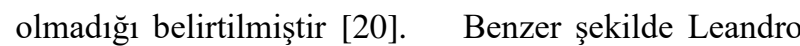
Viçosa Bonetti ve arkadaşları 2018 yılında 19 kadın hentbolcuda $60 \%$ sn, $120 \%$ sn, $180 \%$ sn ve $240 \%$ sn açısal hizlarda dominant ve nondominant diz E-F değerlerini karşılaştırmıştır [20]. Yapılan bu çalışmada $60 \%$ sn açısal hızda dominant bacak diz $\mathrm{E}$ zirve tork değeri $143,59 \pm 39,72(\mathrm{Nm})$, nondominant bacak diz $\mathrm{E}$ zirve tork değeri 144,69 $\pm 33,92(\mathrm{Nm})$; dominant bacak diz F zirve tork değeri $75,35 \pm 20,27(\mathrm{Nm})$, nondominant bacak diz $\mathrm{F}$ zirve tork değeri $72,36 \pm 18,52(\mathrm{Nm})$ bulunmuş ve aralarında anlamlı bir farklılık bildirilmemiştir [21]. Çalışmamıza yakın yüksek açısal hız olan ve çabukkuvvetin değerlendirildiği $240^{\circ} / \mathrm{sn}$ açısal hızda da aynı sonuçlar elde edilmiş ve buna göre dominant bacak diz E zirve tork değeri 79,78 $\pm 14,10$ $(\mathrm{Nm})$, nondominant bacak diz $\mathrm{E}$ zirve tork değeri 81,72 $\pm 17,28(\mathrm{Nm})$; dominant bacak diz F zirve tork değeri $50,28 \pm 8,70(\mathrm{Nm})$, nondominant bacak diz $\mathrm{F}$ zirve tork değeri 47,91 $\pm 10,47(\mathrm{Nm})$ olarak raporlanmıştır [21]. Bu çalışmaların aksine yaptığımız çalışmada ise dominant ve nondominant bacak diz E-F değerleri arasında istatistiksel olarak anlamlı farklılıklar görülmesine rağmen yapılan çalışmalardaki benzer bulguların çalışmamızdaki bulgulardan daha yüksek olduğu görülmüştür.

Atış hızı ve omuz kuvveti hentbol branşı için iki önemli husustur [22]. Hentbolda skor, topun doğru teknik uygulanarak kuvvetli-hızlı omuz ve kol hareketinin gerçekleşmesi ile meydana gelmektedir.

Aynı zamanda farklı bir branş olmasına rağmen omuz İE rotasyon kaslarının yoğun olarak kullanıldığı voleybol branşında 1998 yılında İsveç Kadın A-Milli Takım oyuncularında yapılan bir çalışmada $60 \%$ sn dominant omuz İ kuvvet değerini 40,1 $\pm 3,5(\mathrm{Nm})$, aynı açısal hızdaki omuz E kuvvet değerini 28,1 $\pm 6,7(\mathrm{Nm})$ olarak bulunmuş ve var olan bulgularımıza göre daha düşük değere sahip olduğu görülmüştür [23].

2010 yılında Brezilya Kadın A-Milli Takımının 27 sporcusuyla omuz ölçümleri yaptığı çalışmasında, Andrade ve ark. [24] hentbol kadın sporcuların omuz ölçümlerinde, Alfredson ve ark. [23] 1998 yılında İsveç Kadın A-Milli Takım oyuncularında omuz internal ve eksternal fazlarında dominant ve nondominant zirve tork değerleri sonuçlarını; bizim çalışmalarımızdaki sporcuların sonuçlarından daha yüksek düzeyde bulmuşlardır. Geçiş döneminin uzun olması bu sonuçları etkilemiş olabilir.

Yön değiştirme yeteneği ya da ani hızlanma ve yavaşlama olarak tanımlanan çeviklik performansı, yüksek performans seviyesi için önemli bir faktördür [25,26]. Diz ekstansör kas grupları hızlanma fazında maksimal kasılmanın \%160'ından daha büyük konsantrik hareket tarzı gerçekleştirerek kasılırlarken yavaşlama fazında diz fleksör kas grupları vücut ağırlığının yaklaşık 3 katı kadar yüke karşı devreye girerek çeviklik performansına katkıda bulunurlar $[27,28]$. Bu fizyolojik durumlar dikkatte alındığında diz ekstensör ve fleksör kas grupları kuvvetinin çeviklik ile ilişkili olduğu görülmektedir. Ancak bu konuyla ilgili literatür incelendiğinde çelişkili sonuçlarla karşılaşılmaktadır. Aktuğ ve ark. [29] elit düzeyde 15 erkek hentbolcuyla $60 \%$ sn ve $300 \%$ sn açısal hızlardaki dominant-nondominant diz E-F bacak kuvvetlerinin çeviklik ile olan ilişkisini yaptıkları çalışmayla incelemişler ve istatistiksel olarak anlamlı bir ilişki bulamamışlardır. Yaptığımız çalışmayla aynı paralellikte olan bir başka çalışmada ise Yapıcı [30] 20 profesyonel erkek voleybolcuda $60 \%$ sn ve $300 \%$ sn hizlarda dominantnondominant diz E-F bacak kuvvetlerinin T çeviklik testi ile olan ilişkisini incelemiş ve çalışmamızın sonuçlarında olduğu gibi anlamlı bir ilişki belirtmemiştir. $\mathrm{Bu}$ sonuçların aksine Davis ve ark. [31] futbolcularla yürüttüğü çalışmalarında izokinetik bacak kuvveti ve çeviklik arasında istatistiksel olarak anlamlı farklılık bildirmiştir.

Bir başka çalışmada ise Newman ve ark. [32] futbolcularda $60 \%$ sn, $150 \%$ sn ve $240 \%$ sn hizlarda diz E-F kuvvet ile 0- $10 \mathrm{~m}$ sürat arasinda istatistiksel olarak anlamlı bir ilişki olduğunu bildirmiş̧tir $(\mathrm{r}=-0.714, \mathrm{p}<$ 0.01 ). Literatüre bakıldığında izokinetik bacak kuvveti ve sürat testi arasındaki ilişkinin spor branşına göre farklılık gösterdiği söylenebilir. Yapılan çalışmalar, sürat performansı ve hamstring, quadriceps kas kuvveti arasında pozitif ilişki olduğunu göstermektedir [33, 34]. Ancak yaptığımız çalışmada bu anlamlı pozitif ilişki kurulamamıştır. Bu durumun sebebi olarak sporcuların antrenman programlarında yeterli derecede kuvvet antrenmanlarına yer vermemelerinden dolayı izokinetik dinamometre ölçümü sonucunda düşük hamstring, quadriceps kas kuvveti açığa çıkarmış olmaları gösterilebilir. Aynı zamanda yapılan 0-30 m sürat testinin hentbol branşının sürat fizyolojisine cevap vermemesinden de kaynaklanmış olduğu düşünülebilir. Dolayısıyla performansta fark yaratacak daha kısa mesafelerdeki sürat testi denemelerine odaklanılabilinir. Gentil ve ark. [35] izokinetik ölçüm ve 1 TM ile oluşturulan kas kuvvetini karşılaştırdığı ve ilişkisine baktığı çalışmasında $60^{\circ}$ sn açısal hızdaki izokinetik zirve tork değeri ile $1 \mathrm{TM}$ leg press kuvveti arasında orta düzeyde anlamlı ilişki bulmuştur $(r=0.6 ; p<0.01)$. Ancak 1TM leg press kuvvet değerinin izokinetik zirve tork değerine göre daha yüksek olduğunu bildirmişlerdir. Bir başka çalışmada ise Ferraresi ve ark. [36] 18-24 yaş arasındaki 30 sağlıklı erkek ile yaptıkları çalışmalarında $60 \%$ sn açısal hızda diz E-F izokinetik kuvvet ölçüm değeri ile 1TM leg press kuvvet değerinin arasındaki ilişkiyi incelemiş ve Pearson korelasyon analizine göre 1 TM leg press ve izokinetik ölçümler arasında orta düzeyde bir ilişki olduğunu raporlamışlardır Ancak yaptığımız çalışmada ise anlamlı bir farklılık ortaya konmamıştır. Bu durumun sebebi olarak benzer kas gruplarının çalışmasına rağmen farklı hareket biyomekaniğine sahip olan squat hareketinin kullanılmış olması gösterilebilir.

Yapılan çalışmalarda özellikle futbol branşında vücut kompozisyonu, anaerobik performans, bacak kuvveti ve sırt kuvveti arasındaki ilişkileri tanımlayan çalışmalar olmasına rağmen fiziksel gelişim aşamasında bulunan 
futbolcuların bacak kütle değerleri ile, esneklik, izometrik bacak kuvveti, topa vuruş performansı ve aerobik dayanıklılık kapasitesi arasında ilişkinin incelendiği çalışmalar oldukça sınırlıdır. Literatürde ağırlıklı olarak kuvvet parametreleri ile istatiksel olarak anlamlı ilişki tespit edilen bacak kütle değeri ile aerobik performans arasındaki istatiksel anlamlı ilişkinin meydana gelmesi, yüksek kas kitlesi, yüksek oranda $\mathrm{O}^{2}$ taşınımı ve yüksek aerobik kapasite ile sonuçlanmış olabilir [37].

\section{Sonuç}

$\mathrm{Bu}$ çalışma verilerine göre; özellikle $60 \%$ sn ve $300 \%$ sn açısal hızlarda dominant-nondominant diz ekstansiyonfleksiyon arasında meydana gelen anlamlı kuvvet farklılığın sakatlık oluşumuna neden olmaması ve daha iyi fiziksel performans gelişimi için kadın hentbolcuların kuvvet antrenmanlarına daha fazla yer vermesi önerilmektedir.

Benzer şekilde dominant omuz internal hareketin meydana getirebileceği aşırı kullanım sakatlıklarını engelleme ve dominant-nondominant omuz arasındaki kuvvet farklılıklarını azaltma açısından koruyucu omuz kuvvet programlarına önem verilmesi tavsiye edilebilir. Daha nitelikli kuvvet antrenmanları (İzokinetik egzersiz ile fonksiyonel performansta ve kas kuvvetinde belirgin artış elde edilebilir) yapmaları tavsiye edilebilir.

\section{Teşekkürler}

Yazarlar çalışmaya gönüllü olarak katılan tüm sporculara teşekkürlerini sunmaktadır. Bu araştırma 2018-223 no'lu proje olarak Celal Bayar Üniversitesi Bilimsel Araştırma Projeleri tarafindan desteklenmiştir.

\section{Referanslar}

1. Nomogram to Predict Performance Equivalence for Distance Runners, Track Technique.

2. Matsushigue, Karin A., Hartmann, Franchini, E, Taekwondo: 24. Physiological Responses and Match Analysis, Journal of Strength and Conditioning Research, 2009, 23 (4), 1112-1117.

3. Bělka, J, Hůlka, K et al, Analysis of the Fitness Level in Elite Handball Players (U16 and U18) between 2003 and 2013, Journal 25. of Physical Education and Sport, 2016, 16(4), 1381 - 1390.

4. Machado, S, Aparecido Souza, R, Simão, A, Jerônimo, D, Silva, N, Osorio, R, Magini, M, 2009, Comparative Study of Isokinetic Variables of the Knee in Taekwondo and Kickboxing Athletes, Fitness \& Performance Journal, 2009, 8(6), 407-11.

5. Tortop, Y, Türkmenoğlu İ, Ocak Y. Güreşci ve Futbolcuların Diz Eklemi Fleksiyon ve Ekstansiyon Kas Kuvvetlerinin İzokinetik Dinamometrede Değerlendirilmesi, Gazi Beden Eğitimi ve Spor Bilimleri Dergisi, 2009, 14 (4), 33-47.

6. Eler, S, Bereket S, Elit Türk ve Yabancı Hentbolcuların Motorik ve 28. Fizyolojik Parametrelerinin Karşılaştırılması, Gazi Üniversitesi Beden Eğitimi ve Spor Bilimleri Dergisi, 2001, 6(4), 46-48

7. Gorostiaga, EM, Granados, $\mathrm{C}$ et al, Effects of an entire season on physical fitness changes in elite male handball players, Medicine \& Science in Sports \& Exercise, 2006, 38(2), 357-366.

8. Gorostiaga, EM, Izquierdo, M, Iturralde, P, Ruesta, M, \& Ibáñez, J, Effects of heavy resistance training on maximal and explosive force production, endurance and serum hormones in adolescent handball players, European Journal of Applied physiology, 1999, 80(5), 485493.

9. Wallace, MB, Cardinale, M, Conditioning for Team Handball, Strength and Conditioning, 1997, 19(6), 7-12.
10. Jöris, HJJ, Van Muyen, AE et al, Force, velocity and energy flow during the overarm throw in female handball players, Journal of Biomechanics, 1985, 18(6), 409-414.

11. Cerrah AO, Onarici GE, Soylu AR, Ertan H, Muscular activation differences between professional and amateur soccer players during countermovement jump, Türk Spor ve Egzersiz Dergisi, Cilt 6 Say1:2, 51-58.

12. Bloomfield, J, Polman, R, O’Donoghue, P, McNaughton, L, Effective Speed and Agility Conditioning Methodology for Random Intermittent Dynamic Type Sports, Journal of Strength and Conditioning Research, 2007.

13. Vescovi, JD, McGuigan, MR, Relationships between Sprinting, Agility, and Jump Ability in Female Athletes, Journal of Sports Sciences, 2008.

14. Xaverova Z, Dirnberger J, Lehnert M, Belka J, Wagner $\mathrm{H}$, Orechovska K, Isokinetic strength profile of elite female handball players, J Human Kinetics, 2015, 49, 257-266.

15. Altunışık, R, Coşkun, R, Bayraktaoğlu, S, Yıldırım, E, Sosyal Bilimlerde Araştırma Yöntemleri SPSS Uygulamalı, 2005, 10-20.

16. Brown, LE, Weir JP, 2001, ASEP Procedures Recommendation I: Accurate Assessment of Muscular Strength and Power, Journal of Exercise Physiology Online, 2001, 4(3), 1-21

17. Bottaro, M, André R, Jacó De Oliveira R, The Effects of Rest Interval on Quadriceps Torque during an Isokinetic Testing Protocol in Elderly, Journal of Sports Science Medicine, 2005, 4(3), 285-290.

18. Cerrah, AO, Futbolda Farklı Vurus Tekniklerinde Kassa Aktivasyonların ve Top Hızı Izokinetik Kuvvet Ilişkisinin Değerlendirilmesi, 2009, Anadolu Üniversitesi.

19. Mackenzie, B, Mercier, Daniel, Luc Leger, and Marc Desjardins, Performance Evaluation Tests. 1986

20. Kurdak S, Özgünen K, Adas Ü, Zeren C, Aslangiray B, Yazıcı Z Korkmaz S, Analysis of Isokinetic Knee Extension/Flexion in Male Elite Adolescent Wrestlers, Journal of Sports Science and Medicine, 2005, 4(4), 489-98.

21. Risberg, May A., Kathrin Steffen et al, Normative Quadriceps and Hamstring Muscle Strength Values for Female, Healthy, Elite Handball and Football Players, J Strength Cond Res, 2018, 32(8), 2314-2323

22. Leandro Viçosa, $\mathrm{B}$, Coulon Grisa, $\mathrm{N}$ et al, Isokinetic Performance of Knee Extensor and Flexor Musculature in Adolescent Female Handball Players, Archivos de Medicina Del Deporte, Arch Med Deporte, 2018, 35(3), 157-161

23. Yıldırım, A, Koçak, MS, Korkusuz, F, Effects of Isokinetic Shoulder Strength Training on Throwing Velocity in Collegiate Female Handball Players, Turkiye Klinikleri Journal of Sports Science, 2009, 1(1), 11-16.

24. Alfredson, H, Pietilä, T, Lorentzon, R, Concentric and Eccentric Shoulder and Elbow Muscle Strength in Female Volleyball Players and Non-Active Females, Scandinavian Journal of Medicine \& Science in Sports, 1998, 8(5), 265-270.

25. Marília Dos Santos, A, Fleury AM et al, Profile of Isokinetic Eccentric-to-Concentric Strength Ratios of Shoulder Rotator Muscles in Elite Female Team Handball Players, Journal of Sports Sciences, 2010, 28(7), 743-749.

26. Müller, E, Ulrıke B, Chrıstıan R, Schwameder H, Specific Fitness Training and Testing in Competitive Sports, Medicine \& Science in Sports \& Exercise, 2000, 32(1), p 216.

27. Trninić, S, Marković, G, Heimer S, Effects of Developmental Training of Basketball Cadets Realised in the Competitive Period, Collegium antropologicum, 2001, 25, 2, 591-604.

8. Colby, S. Francisco, A, Yu, B, Kirkendall, D, Finch, M, Garrett, W, Electromyographic and Kinematic Analysis of Cutting Maneuvers. Implications for Anterior Cruciate Ligament Injury, American Journal of Sports Medicine, 2000, 28(2), 204-209.

29. Simonsen, EB, Magnusson SP et al, Can the Hamstring Muscles Protect the Anterior Cruciate Ligament during a Side-Cutting Maneuver? Scandinavian Journal of Medicine and Science in Sports, 2000, 10(2), 78-84.

30. Aktuğ, ZB, Dündar A, Murathan F, İri R, The Determination of the Relationship Between Isokinetic Leg Strengths and Agility and Speed Performance of Elite Handball Players, Journal of Education and Training Studies, 2018, 6(6), 25-30.

31. Yapic1 A, Evaluation of the Relationship between Isokinetic Strength and Field Performance in Professional Male Volleyball Players, European Journal of Physical Education and Sport Science, 2016, 2(6), 1-11. 
32. Davis, D. Scott, Bradley J. Barnette, et al, Physical Characteristics That Predict Functional Performance in Division I College Football Players, Journal of Strength and Conditioning Research, 2004, 18(1), 115-120.

33. Newman, MA, Tarpenning, KM, Marino, FE, Relationships between Isokinetic Knee Strength, Single-Sprint Performance, and RepeatedSprint Ability in Football Players, Journal of Strength and Conditioning Research, 2004, 18(4),867-872.

34. Harris, NK, Cronin, JB, Hopkins, WG, Hansen, KT, Relationship between Sprint Times and the Strength/Power Outputs of a Machine Squat Jump, Journal of Strength Condition Research, 2008, 22(3), 691-98.

35. Smirniotou, A, Katsikas, C, Paradisis, G, Argeitaki, P, Zacharogiannis, E, Tziortzis, S, Strength-power parameters as predictors of sprinting performance, The Journal of sports medicine and physical fitness, 2008, 48, 447-454.

36. Gentil, P, Del Vecchio FB, Paoli et al, Isokinetic Dynamometry and 1RM Tests Produce Conflicting Results for Assessing Alterations in Muscle Strength, Journal of Human Kinetics, 2017, 56, 19-27.

37. Ferraresi, C, Vilmar B, Sérgio EA, Perez, E, M. Júnior, VS. B, Nivaldo AP, One-Repetition Maximum Test and Isokinetic Leg Extension and Flexion: Correlations and Predicted Values, Isokinetics and Exercise Science, 2013, 21, 1, 69-76.

http://edergi.cbu.edu.tr/ojs/index.php/cbusbed isimli yazarın CBU-SBED başlıklı eseri bu Creative Commons Alıntı-Gayriticari4.0 Uluslararası Lisansı ile lisanslanmıştır. 